\title{
CD74 interferes with the expression of fas receptor on the surface of lymphoma cells
}

\author{
Zuzana Berkova', Shu Wang ${ }^{1}$, Xue Ao ${ }^{1}$, Jillian F Wise', Frank K Braun ${ }^{1}$, Abdol H Rezaeian', Lalit Sehgal', \\ David M Goldenberg ${ }^{2,3}$ and Felipe Samaniego ${ }^{1 *}$
}

\begin{abstract}
Background: Resistance to Fas-mediated apoptosis limits the efficacy of currently available chemotherapy regimens. We identified CD74, which is known to be overexpressed in hematological malignancies, as one of the factors interfering with Fas-mediated apoptosis.

Methods: CD74 expression was suppressed in human B-lymphoma cell lines, BJAB and Raji, by either transduction with lentivirus particles or transfection with episomal vector, both encoding CD74-specific shRNAs or non-target shRNA. Effect of CD74 expression on Fas signaling was evaluated by comparing survival of mice hydrodynamically transfected with vector encoding full-length CD74 or empty vector. Sensitivity of cells with suppressed CD74 expression to FasL, edelfosine, doxorubicin, and a humanized CD74-specific antibody, milatuzumab, was evaluated by flow cytometry and compared to control cells. Fas signaling in response to FasL stimulation and the expression of Fas signaling components were evaluated by Western blot. Surface expression of Fas was detected by flow cytometry.

Results: We determined that cells with suppressed CD74 are more sensitive to FasL-induced apoptosis and Fas signaling-dependent chemotherapies, edelfosine and doxorubicin, than control CD74-expressing cells. On the other hand, expression of full-length CD74 in livers protected the mice from a lethal challenge with agonistic anti-Fas antibody J02. A detailed analysis of Fas signaling in cells lacking CD74 and control cells revealed increased cleavage/activation of pro-caspase-8 and corresponding enhancement of caspase-3 activation in the absence of CD74, suggesting that CD74 affects the immediate early steps in Fas signaling at the plasma membrane. Cells with suppressed CD74 expression showed increased staining of Fas receptor on their surface. Pre-treatment with milatuzumab sensitized BJAB cells to Fas-mediated apoptosis.

Conclusion: We anticipate that specific targeting of the CD74 on the cell surface will sensitize CD74-expressing cancer cells to Fas-mediated apoptosis, and thus will increase effectiveness of chemotherapy regimens for hematological malignancies.
\end{abstract}

\section{Background}

CD74, better known as an invariant chain (Ii) of the major histocompatibility complex II (MHC II) [1-3], is indispensable for the proper development of $\mathrm{B}$ cells. CD74 is internalized into the endocytic compartment, where intramembrane cleavage releases the intracellular cytosolic domain (CD74-ICD). CD74-ICD then enters the nucleus, activates NF-kB p65/RelA, and controls the differentiation of B cells through the TAFII105 coactivator [4,5]. CD74ICD also induces expression of TAp63, which subsequently

\footnotetext{
* Correspondence: fsamaniego@mdanderson.org

'Department of Lymphoma and Myeloma, The University of Texas MD Anderson Cancer Center, 1515 Holcombe Blvd., Houston, TX 77030, USA Full list of author information is available at the end of the article
}

elevates expression of $\mathrm{Bcl}-2$ and promotes survival of $\mathrm{B}$ cells [6]. Macrophage migration inhibitory factor (MIF) is the assigned ligand for CD74 and its binding activates the extracellular signal-regulated kinase-1/2 (ERK 1/2) MAP kinase (MAPK) cascade and cell proliferation [7], as well as NF- $\mathrm{kB}$, through which it enhances the expression of $\mathrm{Bcl}-2$ [6].

CD74 expression is rather limited in normal human tissues, but it was found to be overexpressed in more than $85 \%$ of non-Hodgkin lymphoma (NHL), chronic lymphocytic leukemia (CLL) and a majority of multiple myeloma (MM) cells [8-12]. B cells from CLL patients have higher cell surface levels of CD74 than do normal $\mathrm{B}$ cells, and it was shown that the activation of CD74 
by MIF in CLL cells activates NF-kB and induces secretion of IL-8, which promotes cell survival and tumor progression [11,13]. CD74-mediated proliferative and pro-survival signaling can initiate or contribute to procarcinogenic events and enhance the survival of cancer cells.

The Fas receptor is widely expressed by many tissues, yet the extent of Fas-mediated apoptosis does not correlate with the extent of Fas expression. Hematological cancer cells are commonly resistant to Fas ligand (FasL)-induced apoptosis despite normal expression of the Fas receptor [14]. This resistance is usually not caused by Fas/FasL mutations or overexpression of apoptosis inhibitors, such as cFLIP (cellular FLICE/caspase-8-inhibitory protein) [15]. Identification of potential inhibitors of Fas-mediated apoptotic signaling in cancers and understanding of the mechanism involved are important steps necessary for the design and implementation of new targeted therapies. Reversing Fas resistance has become a primary interest in order to improve the efficacy of treatments for chemotherapyresistant hematological cancers [16-19]. Several current treatments, like interferon gamma (IFN- $\gamma$ ), CD40L, and rituximab, are believed to improve responses to chemotherapy primarily through restoration of Fas apoptotic signaling $[16,17,20,21]$. Our goal was to identify and to target inhibitors of the Fas receptor in order to reinstate Fas-mediated apoptotic signaling in cancer cells with limited off-target effects on normal cells.

In the light of well documented CD74-mediated prosurvival effects, we aimed to examine the effect of CD74 on Fas-mediated apoptosis, which is required for effective killing of cancer cells by most chemotherapies and radiation [22-26].

\section{Methods}

\section{Cell lines and drug treatments}

BJAB, Raji, Ramos, Daudi, and Jurkat cells were purchased from ATCC and grown in RPMI medium with 10\% FBS (HyClone) in a $5 \% \mathrm{CO}_{2}$ atmosphere at $37^{\circ} \mathrm{C}$, and split 2-3 times per week. Cell lines were authenticated by STR analysis (MD Anderson Cancer Center Characterized Cell Line Core) and regularly tested for mycoplasma (Lonza).

For drug treatment, $0.5 \mathrm{e} 6$ cells $/ \mathrm{mL}$ in RPMI + 5\% FBS were seeded into 24-well plates and treated with indicated doses of FasL (Enzo) or edelfosine (SigmaAldrich) for 20 hours, doxorubicin (Sigma-Aldrich) for $48 \mathrm{~h}$, or $10 \mathrm{ng} / \mathrm{mL}$ of super FasL (sFasL; Enzo) for $16 \mathrm{~h}$.

BJAB cells (1e6 cells $/ \mathrm{mL}$ ) were incubated with $50 \mu \mathrm{g} / \mathrm{mL}$ of milatuzumab (humanized anti-CD74 antibody, hLL1; Immunomedics, Inc.) for $10 \mathrm{~min}$ prior to addition of $20 \mu \mathrm{g} /$ $\mathrm{mL}$ of goat anti-mouse or goat anti-human IgG (both from Jackson ImmunoResearch). Cells were washed after $30 \mathrm{~min}$ and subsequently incubated with either $50 \mathrm{ng} / \mathrm{mL}$ of antiFas antibody CH-11 (Millipore) or recombinant FasL (Enzo).
Cells were harvested $24 \mathrm{~h}$ later and analyzed for apoptosis by propidium iodide staining and flow cytometry, as described previously [27].

\section{Cloning and RNA interference}

To knock-down CD74 expression, BJAB and Raji cells were transduced using MISSION shRNA lentiviral particles targeting CD74 or non-target (NT) controls, according to manufacturer's protocol (Sigma-Aldrich), and kept under selection with $1.9 \mu \mathrm{g} / \mathrm{mL}$ of puromycin.

The shRNA sequences from MISSION shRNA lentiviral particles were inserted between BamHI and EcoRI restriction sites in the multiple cloning cassette of pSIRENShuttle vector (Clontech). The U6 promoter-shRNA cassettes were then recloned to KpnI and ApaI sites of the pEPI-1 vector kindly provided by Dr. A. C. Jenke (HELIOS Children's Hospital Wuppertal, Germany) [28]. The correct sequences of inserted shRNAs were confirmed by sequencing (SeqWright).

Obtained plasmids were transfected into cells using Lipofectamine 2000 transfection reagent (Invitrogen) according to the manufacturer's recommendations. Transfected cells were sorted $48 \mathrm{~h}$ post transfection based on green fluorescent protein (GFP) expression, using a flowactivated cell sorter BD FACSAria II (BD Biosciences) followed by limited dilutions and selection with geneticin (1350 $\mu \mathrm{g} / \mathrm{mL}$; Invitrogen) for 2 weeks.

\section{Western Blotting (WB)}

WB was performed according to standard protocols, as described previously $[29,30]$. Protein expression in total cell lysates was analyzed with primary antibodies recognizing Fas (B-10), CD74 (LN-2), cFLIP, caspase-8 and caspase-3 [all at 1:1,000 dilution in 5\% blotting-grade blocker (BioRad) in phosphate-buffered saline (PBS) with Tween 20], followed by anti-mouse-HRP or antirabbit-HRP antibodies when an unconjugated primary antibody was used. Equal loading was verified by $\beta$-actinHRP antibody (1:10,000; Sigma-Aldrich). Visualization was achieved by Supersignal West Pico chemiluminescent substrate (Thermo Scientific). Intensity of bands was compared by densitometry using ImageJ software (NIH).

\section{Flow cytometry}

For detection of surface Fas or CD74, cells were washed with $2 \% \mathrm{FBS} / \mathrm{PBS}$ and blocked with $0.025 \mathrm{mg} / \mathrm{mL}$ of mouse IgG blocking reagent (Invitrogen) at $4^{\circ} \mathrm{C}$ for $15 \mathrm{~min}$ in the dark and washed once with $2 \%$ FBS/PBS. Cells were then incubated with $3 \mu \mathrm{L}$ of PE-conjugated anti-Fas antibody UB2 or with FITC-conjugated anti-CD74 antibody M-B741 (both from BD Biosciences) in $50 \mu \mathrm{L}$ of $2 \% \mathrm{FBS} / \mathrm{PBS}$ at $4^{\circ} \mathrm{C}$ for $20 \mathrm{~min}$ in the dark. After washing cells $2 \times$ with $2 \% \mathrm{FBS} /$ PBS, flow cytometry was performed on an BD LSRFortessa flow cytometer with Diva software (BD Bioscience). 
For evaluation of apoptosis and cell death, cells were collected and resuspended in $1 \mathrm{~mL}$ of cold 1\% FBS/PBS and stained with Vybrant ${ }^{\oplus}$ Apoptosis Assay Kit \#5 according to protocol provided by the manufacturer (Molecular Probes). Flow cytometry was performed on BD FACSCanto II flow cytometer with Diva software (BD Bioscience). Data were analyzed using FlowJo software (Tree Star Inc.).

\section{Animal experiments and immunohistochemistry}

All animal experiments were performed in accordance with the guidelines of MD Anderson Cancer Center's Institutional Animal Care and Use Committee. C57BL/6 mice (6- to 8-weeks old; from the National Cancer Institute) were hydrodynamically transfected [31] with $100 \mu \mathrm{g}$ of plasmid (pEF4-myc or pEF4-CD74-myc [4]; kindly provided by Dr. Idit Shachar, The Weisman Institute of Science, Rehovot, Israel). Mice were challenged with agonistic anti-Fas antibody Jo2 $(0.4 \mu \mathrm{g} / \mathrm{g}$; BD Biosciences) $24 \mathrm{~h}$ post transfection and monitored for survival up to $6 \mathrm{~h}$ post challenge. Livers were harvested at the time of death/sacrifice, paraffin embedded, and cut to $5 \mu \mathrm{m}$ sections.

Formalin-fixed, paraffin-embedded liver tissue sections on microscope slides were treated with an unmasking kit (1:500; Vector Laboratories). Sections were then stained with hematoxylin and eosin (H\&E; both from Fisher Scientific). Immunohistochemical staining was performed using a mouse monoclonal anti-myc antibody (1:500; Sigma-Aldrich) and a rabbit polyclonal anti-cleaved caspase-3 antibody (1:500; Cell Signaling), followed by staining and developing with an $\mathrm{ABC}$ staining kit (Vector Laboratories), according to manufacturer's protocol. Stained samples were viewed using a Zeiss Axioskop 2 plus microscope (Carl Zeiss) with $4 \times$ and $20 \times$ magnification objectives.

\section{Statistical analysis}

Differences between groups were calculated using the two-tailed Student $t$ test. $P$-values less than 0.05 were considered statistically significant.

\section{Results}

\section{CD74 expression in lymphoma cell lines can be suppressed by shRNAs}

To study the effects of CD74 on Fas-mediated apoptosis, we first tested CD74 expression in 4 B-lymphoma cell lines (BJAB, Ramos, Raji, and Daudi) and in the Jurkat (Tcell leukemia) cell line by WB. All four B-lymphoma cell lines expressed CD74, with the lowest expression in Ramos cells (Figure 1A). Daudi cells expressed CD74, but they are known to lack Fas on the cell surface [32]. Thus, the $B J A B$ and Raji cell lines were selected for further analysis.
CD74 expression was first suppressed by transduction of cells with lentiviral particles encoding CD74-targeting shRNAs (\#35, \#36, \#37, \#39) or non-target control shRNA (NT). Cells transduced with particles encoding shRNA 35 and 36 showed a significant decrease of total cellular CD74 (Figure 1B) and surface CD74 (data not shown) when compared to NT shRNA controls. To exclude possible effects of a random incorporation of lentiviral sequences into the genome, we recloned CD74targeting shRNAs 35 and NT into a mammalian-based episomal vector pEPI-1, which was shown previously to generate stable knock-downs without incorporation into the genome [28]. The generated pEPI-shRNA-35 and -NT plasmids were used to generate stable CD74 knock-downs in BJAB cells, BJAB Epi 5.7 and N.7 (Figure 1B).

\section{Downregulation of CD74 sensitizes cells to Fas-mediated apoptosis and to Fas-dependent chemotherapeutic agents}

The pro-survival and anti-apoptotic effects of CD74 are well documented. We thus explored the effects of CD74. downregulation on Fas-mediated apoptosis that plays an important role in responses to chemotherapy.

Cell lines were also tested for their sensitivity to superFasL. All 3 pairs of CD74 knock-down and control (nontarget) cells showed significantly increased sensitivity of CD74 knock-down cells to Fas-mediated apoptosis (Figure 2A) independently of the method used to generate the knock-downs (episome vs. lentivirus). Importantly, there were no significant differences in FasL-induced apoptosis between pairs of BJAB Epi (N.7 vs 5.7) and BJAB Lenti (NT vs. 35$)$ cells $(18 \pm 0.1 \%$ vs. $36 \pm 3.3 \%$ and $20 \pm$ $1.5 \%$ vs. $35 \pm 0.1 \%$, respectively; both pairs $P<0.01$ ). Because downregulation of CD74 using episomal vector (BJAB Epi 5.7) turned out to be more stable than lentiviral particles (BJAB Lenti 35 and Raji Lenti 35; data not shown), BJAB Epi cells were selected for all subsequent experiments.

Incubation of BJAB Epi cells with increasing doses of FasL revealed that cells with downregulated CD74 were more sensitive to Fas-mediated apoptosis than control (non-target) cells at all tested FasL concentrations (Figure 2B), without significant differences in basal apoptosis ( $0 \mathrm{ng} / \mathrm{mL}$ of FasL).

Edelfosine was shown to kill cancer cells by a ligandindependent crosslinking of Fas receptor [33]. We thus tested the effect of CD74 downregulation on edelfosineinduced cell killing. As expected, cells lacking CD74 were sensitized to the standard $(10 \mu \mathrm{M})$ dose of edelfosine when compared to control (non-target) cells (64 \pm $1 \%$ vs. $36 \pm 7 \% ; P<0.001$ ) (Figure $2 \mathrm{C}$ ).

Doxorubicin (DOX) is a very potent anti-cancer drug used to treat lymphoma and other cancers. It is well known that cells with defective Fas signaling are 


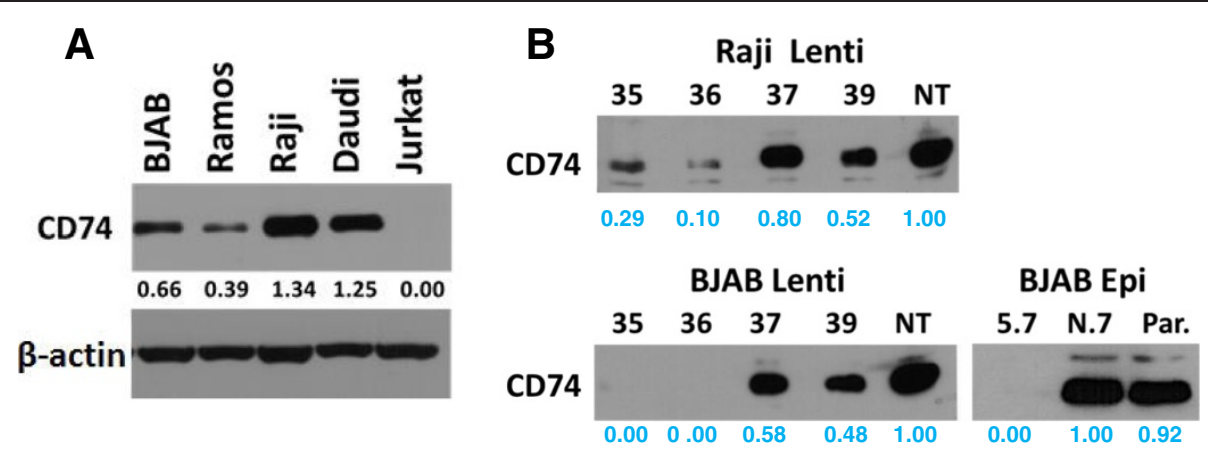

Figure 1 Establishment of CD74 knock-down cells. (A) Indicated lymphoma cell lines were harvested, lysed and CD74 expression was detected by WB using anti CD74 antibody LN-2. $\beta$-actin staining was used as a loading control; (B) BJAB Lenti and Raji Lenti cell lines with CD74 expression knocked-down with lentiviral vectors encoding CD74 targeting shRNAs (Sigma-Aldrich, 35, 36, 37, 39) or no-target shRNA (NT) and BJAB Epi cells with shRNAs expressed from the episomal vector (CD74 knock down cells clone 5.7, no-target cells clone N.7 and parental cells - Par) were harvested, lysed and analyzed for the expression of CD74 as in (A).
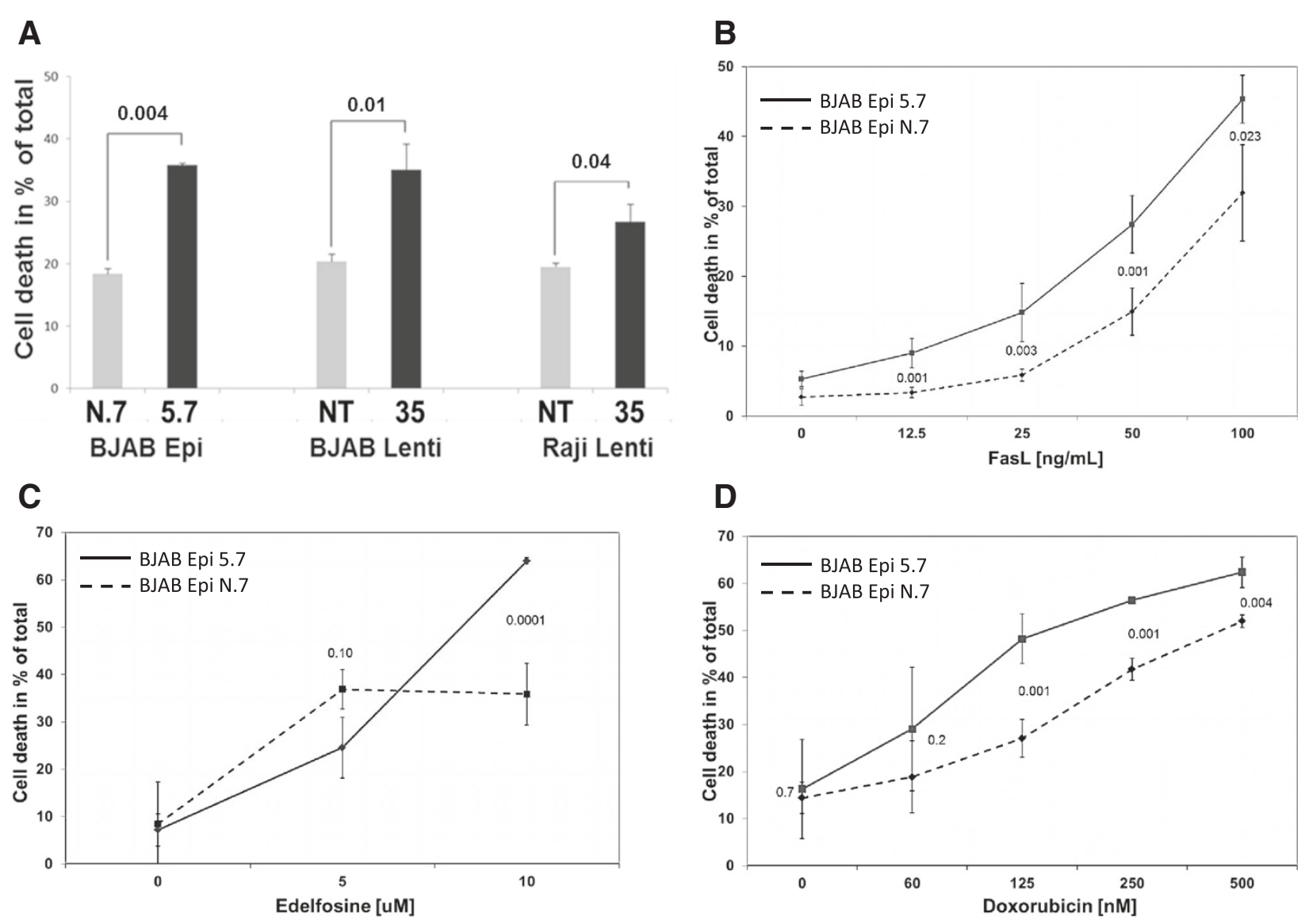

Figure 2 Suppression of CD74 expression sensitizes lymphoma cell lines to Fas-mediated apoptosis and Fas-dependent chemotherapies. Cell death was evaluated by flow cytometry in (A) BJAB Epi (clones 5.7 and N.7), BJAB Lenti (clones 35, NT), Raji Lenti (clones 35, NT) cells treated with $20 \mathrm{ng} / \mathrm{mL}$ of superFasL for 20 hours, (B) BJAB Epi clones 5.7 (solid line) and N.7 (dashed line) treated with indicated concentration of FasL for 20 hours, (C) BJAB Epi clones 5.7 (solid line) and N.7 (dashed line) treated with indicated concentration of edelfosine for 20 hours; (D) BJAB Epi clones 5.7 (solid line) and N.7 (dashed line) were treated with indicated concentrations of doxorubicin for 48 hours. Values shown represent the average and standard deviation from 3 wells. Presented results are a representative of at least two independent experiments. 
resistant to killing by DOX [23]. Responses to DOX were enhanced in cells lacking CD74 (Figure 2D). Notably, cell death induced by $125 \mathrm{nM}$ DOX in CD74 knock-down cells was comparable to cell death induced by $500 \mathrm{nM}$ DOX in control (no-target) cells $(48.2 \pm 5.3 \%$ vs. $52.00 \pm 1.3 \% ; P=0.8$.

\section{Overexpression of CD74 confers resistance to Fas- mediated apoptosis}

The expression of Fas receptor in the liver tissue is very high, which makes liver extremely sensitive to Fas-mediated apoptosis and injection of Fas agonists into mice causes death due to hepatic failure [34].

We used hydrodynamic transfection to transiently express CD74 in mouse livers [31]. Subsequent challenge with a lethal dose of anti-Fas antibody Jo2 killed all 5 Myc-tag vector- transfected mice, while 5 of 6 mice transfected with plasmid encoding Myc-tagged CD74 (CD74-Myc) remained alive at the end of the experiment, $6 \mathrm{~h}$ post challenge (Figure 3A; $P=0.015$ ). Livers of vector-transfected mice challenged with Jo2 appeared dark and swollen due to intensive diffuse hemorrhaging, whereas livers of mice expressing CD74-Myc showed only very little or no hemorrhaging (Figure 3B).
Hematoxylin and eosin (H\&E) staining of the harvested liver tissues confirmed extensive vs. limited hemorrhaging in vector- vs. CD74-Myc-expressing livers challenged with Jo2 (Figure 3C; H\&E). Expression of CD74-Myc in transfected livers was confirmed by immunohistochemistry using anti-Myc antibody (Figure 3C; Myc). Further magnification confirmed positive staining in polygon-shaped cells that contained centrally located nuclei, characteristics of hepatocytes [Figure 3C; Myc(6x zoom)].

Staining of liver sections with anti-cleaved caspase-3 antibody to evaluate apoptosis revealed higher staining intensity in the livers of vector-transfected mice compared to CD74Myc-transfected livers (Figure 3C; Cleaved Caspase-3), confirming that expression of CD74 interferes with Fasmediated apoptosis.

\section{Downregulation of CD74 enhances processing of pro-caspase-8}

To pinpoint which step in the Fas-mediated apoptosis cascade is affected by CD74, we treated CD74-deficient BJAB Epi 5.7 and control BJAB Epi N.7 cells with sFasL, and analyzed the processing/activation of the initiator caspase- 8 and the executioner caspase- 3 by WB (Figure 4A). This analysis revealed that the activation of
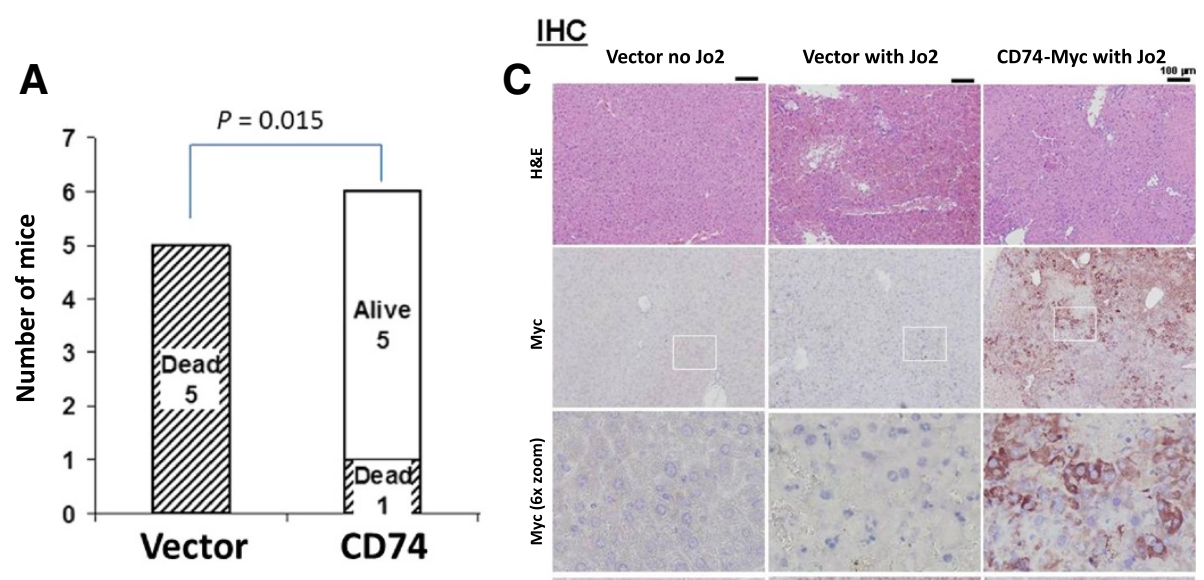

B
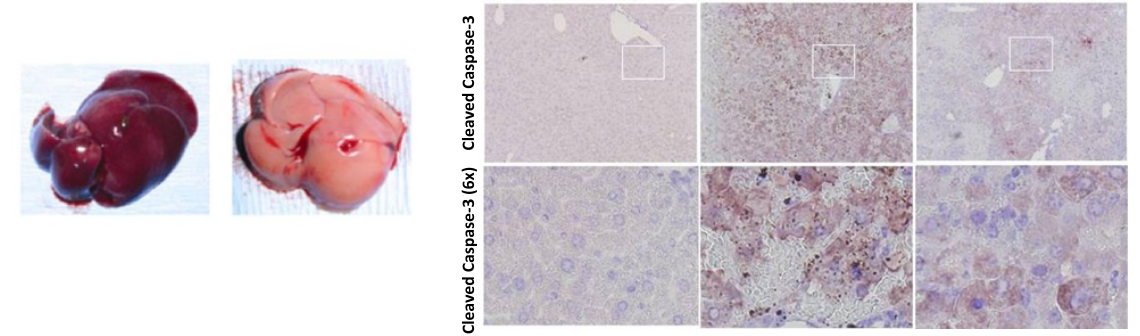

Figure 3 Over-expression of CD74 protects mice from a lethal dose of agonistic Fas antibody. Mice were transfected with an empty plasmid (vector) or plasmid encoding Myc-tagged CD74 using a hydrodynamic transfection method. Twenty-four hours post transfection, mice were challenged with a lethal dose of agonistic anti-Fas antibody Jo2 and monitored for survival up to 6 hours. (A) Survival of challenged mice at 6 hours; (B) gross appearance of livers from Jo2 challenged mice; (C) immunohistochemistry of liver tissues from control (vector) and Jo2-challenged (vector with Jo2 and CD74-Myc with Jo2) mice. H\&E - hematoxylin and eosin staining, MYC - Myc-tag staining, Cleaved Caspase 3 - apoptosis staining. 


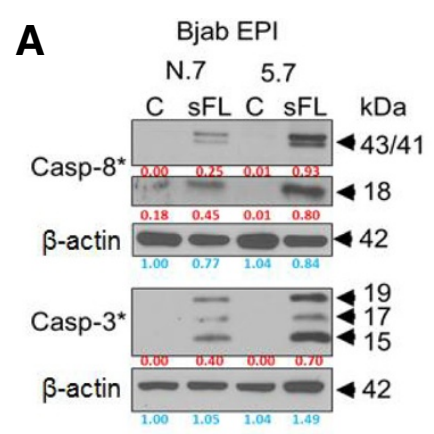

C

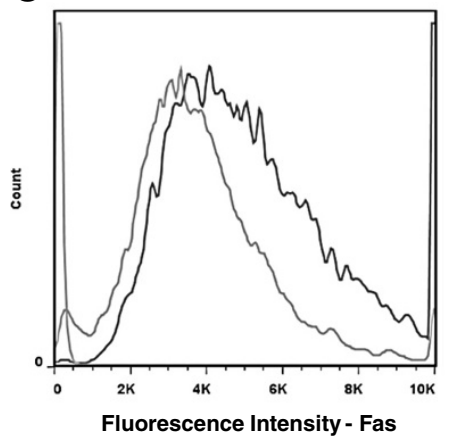

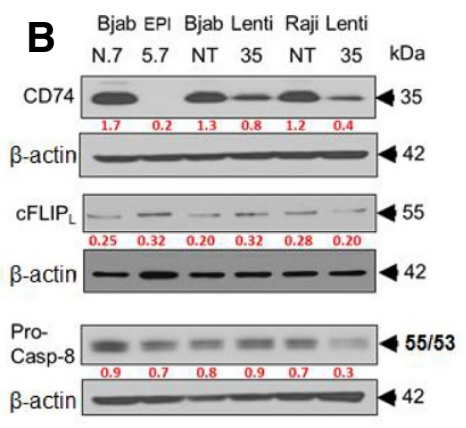

D

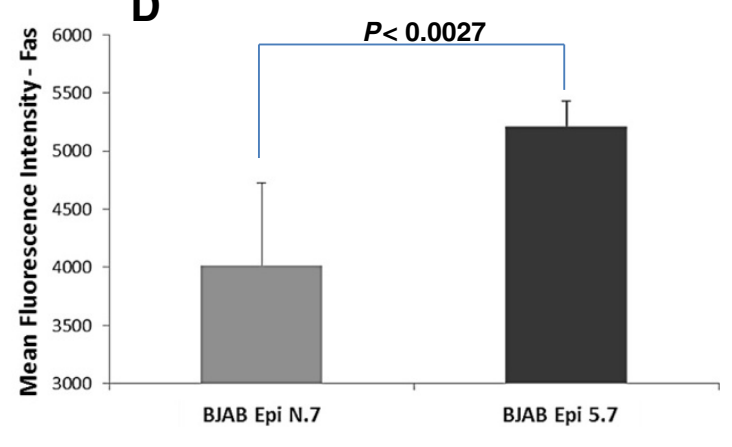

Figure 4 Knock-down of CD74 sensitizes lymphoma cell lines to Fas-mediated apoptosis and increases Fas receptor levels on the cell surface. (A) BJAB Epi cells (clones 5.7 and N.7) were treated with 20 ng/mL of super FasL (sFL) or buffer (C) for 20 hours. Cells were harvested, lysed and processing of caspase- 8 and caspase-3 was detected by Western blot using antibodies specific for cleaved forms of either caspase. B-actin staining was used as a loading control; (B) BJAB Lenti and Raji Lenti cell lines (clones 35, NT) and BJAB Epi cells (clones 5.7 and N.7) were harvested, lysed and analyzed for the expression of CFLIP and pro-caspase- 8 using specific antibodies. $\beta$-actin staining was used as a loading control; (C) BJAB Epi cells (clones 5.7 and N.7) were stained with PE-conjugated anti-Fas antibody UB2 and analyzed by flow cytometry. Data shown are representative of 3 independent experiments; (D) graphic representation of flow cytometry analysis of BJAB Epi cells (clones 5.7 and N.7) stained with PE-conjugated anti-Fas antibody UB2 and positively selected for green fluorescent protein signal. Values shown represent means and standard deviations from 3 wells.

caspase- 8 and corresponding activation of downstream caspase-3 were enhanced in cells lacking CD74. This result suggests that CD74 interferes with an early membrane proximal step in the Fas signaling cascade that affects activation of caspase- 8 .

The membrane proximal signaling of Fas receptor can be affected by the levels of Fas receptor expressed on the cell surface and/or the efficiency of ligand binding, as well as by the inhibitor of caspase-8, cFLIP. We first focused our attention to the levels of cFLIP, expression, which is known to be upregulated by NF- $\mathrm{kB}$ that was shown to be activated by CD74 [6]. Comparison of protein levels in whole cell lysates from CD74 knock-down and control (non-target) cells by WB analysis showed that CD74 downregulation did not significantly affect steady-state levels of $\mathrm{CFLIP}_{\mathrm{L}}$ in BJAB Epi or Lenti cells when compared to control cells (Figure 4B). The levels of cFLIP $\mathrm{L}_{\mathrm{L}}$ target, caspase-8, were also not affected by the CD74 knock-down (Figure 4B). This result suggested that increased sensitivity to Fas-mediated apoptosis in CD74 downregulated cells is not due to decreased expression of $\mathrm{CFLIP}_{\mathrm{L}}$ or increased expression of caspase-8.
We next compared the levels of Fas receptor expressed on the surface of the cells by flow cytometry, which revealed significantly elevated levels of surface Fas in CD74 dowregulated BJAB Epi cells compared to control (non-target) cells (Figure 4C-D). Similar results were obtained in BJAB Lenti and Raji Lenti cells, which showed $17.1 \pm 5.5 \%$ and $14.4 \%$ increases in the MFI in CD74 knock-down cells, respectively.

\section{Pre-treatment of cells with crosslinked anti-CD74} antibody sensitizes cells to Fas-mediated apoptosis We next tested the ability of the humanized anti-CD74 antibody (hLL1; milatuzumab) to sensitize BJAB cells to Fas-mediated apoptosis. Pre-treatment of cells with hLL1 combined with crosslinking antibody potentiated apoptotic responses to agonistic Fas antibody $\mathrm{CH}-11$, as well as FasL (Figure 5).

\section{Discussion}

In the presented study we evaluated the effect of CD74 on the Fas-mediated apoptotic signaling in lymphoma cells by knocking down the expression of CD74 in $\mathrm{BJAB}$ and 


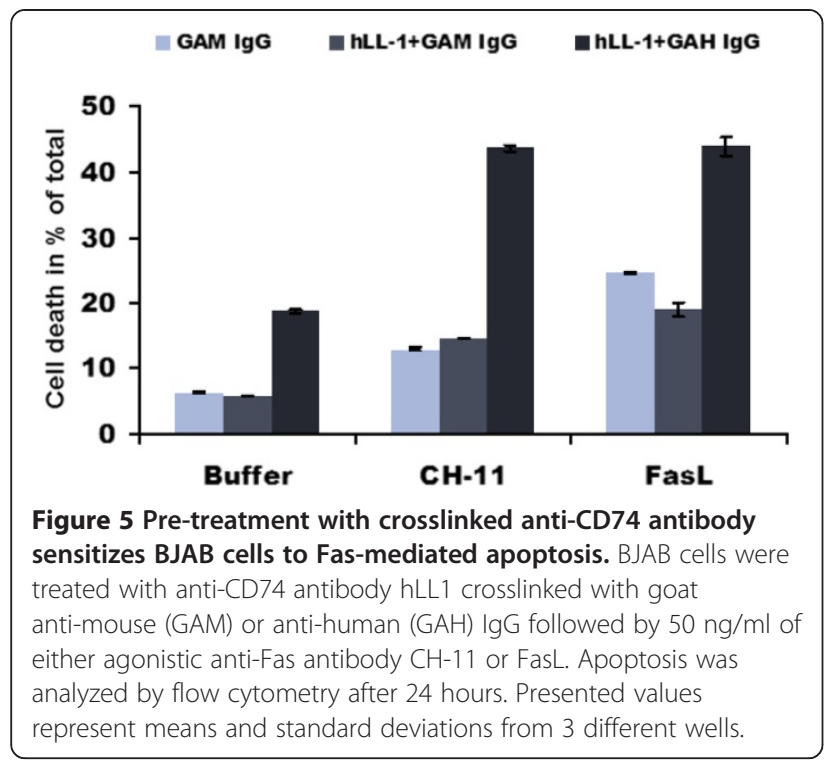

Raji human NHL cells. We successfully generated the first cell lines with stable knock-down of CD74 expression by lentiviral and episomal vectors expressing CD74-targeting shRNA (Figure 1B). Using these cell lines, we showed that removal of CD74 sensitizes cells to Fas-mediated apoptosis (Figure 2A-B) and subsequently also to Fasdependent chemotherapies, doxorubicin and edelfosine (Figure 2C-D). On the other hand, the overexpression of CD74 in mouse livers protected mice from the lethality of agonistic Fas antibody Jo2 (Figure 3A) by interfering with apoptotic signaling (Figure $3 \mathrm{C}$ ). Increased sensitivity to Fas-mediated apoptosis in cells lacking CD74 was due to increased activation/cleavage of the initiator caspase8 and correspondingly increased activation of effector caspase-3 (Figure 4A). These results suggested that the enhancement of Fas-mediated apoptosis occurs at an immediate early step of Fas signaling at the plasma membrane - the activation of death-inducing signaling complex (DISC). MIF signaling through CD74 mediates activation of NF- $\mathrm{kB}$, which is known to regulate expression of cFLIP, a well-known inhibitor of a DISC component caspase-8. However, the WB analysis of the steady-state levels of cFLIP and caspase-8 in control and CD74 knockdown cells did not reveal significant alterations of either cFLIP or pro-caspase-8 levels (Figure 4B), suggesting that the Fas signaling component responsible for the sensitization event due to CD74 removal being upstream of DISC assembly. We next tested and confirmed that removal of CD74 significantly increased the levels of Fas receptor at the cell surface (Figure 4C-D) and thus the amount of the Fas receptor available for activation. Moreover, pre-treatment of cells with crosslinked anti-CD74 antibody sensitized cells to Fas-mediated apoptosis (Figure 5).
The inherent or acquired chemoresistance is a common hindrance to the successful treatment of cancer. Multiple chemotherapies, including doxorubicin, have been shown to upregulate Fas and/or FasL in order to achieve their full effectiveness [24,25,35-39]. However, cancer cells frequently downregulate the key players in the Fas signaling cascade or upregulate apoptosis inhibitors (cFLIP, IAPs, and Bcl-2 family members) to avoid apoptosis [30,40,41]. Recently, a new category of Fas inhibitors has been recognized; cell surface receptors HGFR/c-MET, human herpesvirus-8 K1, CD44v6/v9, and nucleolin can bind and block the initiation of Fas signaling at the plasma membrane $[27,29,42-44]$.

The increasing body of evidence points to CD74, known as the invariant chain of the major histocompatibility complex II (MHC II), functioning apart from that at MHC II. It was shown that CD74 serves as a receptor for the macrophage migration inhibitory factor, MIF. MIF-binding to CD74 activates the extracellular signal-regulated kinase-1/2 MAP kinase cascade and cell proliferation [7]. CD74 is overexpressed in a wide variety of cancers (gastric, thymic, colorectal, breast, renal and lung carcinomas, invasive thymomas, bladder, prostate and pancreatic cancers) [9,12,45-50]. Additionally, the vast majority of NHL, CLL, and MM express CD74 while limited expression is observed in normal hematopoietic tissues [8-12]. In CLL cells, MIF was shown to activate NF- $\mathrm{kB}$ signaling, promoting the expression of IL-8 and consequently cell survival $[11,13]$. The surface expression levels of CD74 in hematological cancer cells and some solid tumors correlate with poor prognosis $[45,51,52]$.

A rapid internalization of CD74 ( $10^{6}$ to $10^{7}$ molecules/ cell/day) in a wide range of cancer cells [53], which is not affected by the binding of the mouse monoclonal anti-CD74 antibody LL1 [54], give rise to several therapeutic approaches. LL1 linked with different radioisotopes greatly delayed growth of disseminated Raji lymphoma cells in a xenograft model and cleared tumors in 50\% of the mice [55]. In the second approach, doxorubicin (DOX) conjugated to LL1 (LL1-DOX) cleared disseminated Raji lymphoma xenografts in $90 \%$ of mice. More importantly, the DOX dose used was $2.5 \%$ of the maximum tolerated dose of free DOX [56]. Multiple myeloma is in general difficult to treat. A single dose of LL1-DOX (IMMU-110, Immunomedics, Inc.) cleared multiple myeloma xenografts in $70 \%$ of mice and significantly prolonged survival [57].

The humanized form of LL1 (hLL1 or milatuzumab, Immunomedics, Inc.) alone showed promising antitumor effects in disseminated Raji and Daudi NHL xenograft models [58], and in multiple myeloma xenograft models [59]. Unlike the cell killing mechanism employed by rituximab, milatuzumab-mediated elimination of tumor cells does not involve antibody-dependent cell-mediated cytotoxicity $(\mathrm{ADCC})$ or a complement-dependent cytotoxicity 
(CDC) [58]. It was demonstrated that milatuzumab combined with a crosslinking antibody induces aggregation of CD74 on the cell surface of CLL cells [60]. In another report, crosslinked milatuzumab induced significant apoptosis at $48 \mathrm{~h}$, accompanied with activation of caspase- 8 and caspase- 3 [58], suggesting the involvement of an extrinsic (receptor-mediated) apoptotic pathway. Our results suggest an explanation of those results. A rapidly internalized CD74 (turnover completed in $10 \mathrm{mi}-$ nutes) can decrease the levels of surface Fas (Figure 4C-D) through its internalization from the cell surface. Crosslinked milatuzumab-induced aggregation of CD74 prevents internalization of CD74 [60] and indirectly also internalization of Fas, consequently increasing surface Fas levels and sensitizing cells to Fas-mediated apoptosis (Figure 5).

\section{Conclusions}

We conclude that CD74 regulates Fas death receptor signaling in lymphomas by decreasing the levels of Fas receptor on the cell surface. The exact mechanism of CD74-mediated down-regulation of surface Fas remains unclear and deserves further investigation. Taking into account the frequent CD74 expression in cancers together with the impaired Fas signaling associated with chemoresistance, we extrapolate that $\mathrm{CD} 74$ also contributes to chemoresistance. Thus, addition of CD74-targeting antibody milatuzumab to current chemotherapy regimens can offer new therapeutic interventions, as also suggested in prior studies in multiple myeloma models [59]. Future clinical studies should determine whether milatuzumab can indeed restore Fas-signaling and chemotherapy responses in lymphoma, CLL, and potentially other CD74-expressing malignancies.

\section{Competing interests}

Dr. Goldenberg is employed by and has stock in Immunomedics, Inc., which has patented and owns the milatuzumab antibody used in this study. There are no other potential conflict of interests relevant to this article.

\section{Authors' contributions}

ZB designed the experiments, generated and initially characterized CD74-suppressed cell lines and wrote the manuscript; SW performed animal and milatuzumab experiments; XA performed experiments with chemotherapeutic agents; JFW analyzed surface expression of Fas; FKB and LS performed Western blot analyses; AHR performed immunohistochemistry; $D M G$, and FS designed the experiments and wrote the manuscript. All authors read and approved the final manuscript.

\section{Acknowledgements}

This work was supported by grants from the American Cancer Society (118447-MRSG-10-052-01-LIB to ZB), the National Institutes of Health (CA1206173, CA153170, CA158692, and DK091490 to F.S.), and the Leukemia \& Lymphoma Society (R6132-06 and R6187-09 to F.S.). We also thank the Richard Spencer Lewis Foundation, patients and their families for their support and willingness to join us in our efforts in developing new therapies for lymphoma.

\section{Author details}

'Department of Lymphoma and Myeloma, The University of Texas MD Anderson Cancer Center, 1515 Holcombe Blvd., Houston, TX 77030, USA. ${ }^{2}$ Immunomedics, Inc., Morris Plains, NJ 07950, USA. ${ }^{3}$ Center for Molecular Medicine and Immunology, Garden State Cancer Center, Morris Plains, NJ 07950, USA.

Received: 29 July 2014 Accepted: 22 September 2014

Published online: 10 October 2014

\section{References}

1. Shackelford DA, Strominger JL: Demonstration of structural polymorphism among HLA-DR light chains by two-dimensional gel electrophoresis. J Exp Med 1980, 151:144-165.

2. Jones PP, Murphy DB, Hewgill D, McDevitt HO: Detection of a common polypeptide chain in I-A and I-E sub-region immunoprecipitates. Mol Immunol 1979, 16:51-60.

3. Long EO, Strubin M, Wake CT, Gross N, Carrel S, Goodfellow P, Accolla RS, Mach B: Isolation of CDNA clones for the p33 invariant chain associated with HLA-DR antigens. Proc Natl Acad Sci U S A 1983, 80:5714-5718.

4. Becker-Herman S, Arie G, Medvedovsky H, Kerem A, Shachar I: CD74 is a member of the regulated intramembrane proteolysis-processed protein family. Mol Biol Cell 2005, 16:5061-5069.

5. Matza D, Lantner F, Bogoch Y, Flaishon L, Hershkoviz R, Shachar I: Invariant chain induces $B$ cell maturation in a process that is independent of its chaperonic activity. Proc Natl Acad Sci U S A 2002, 99:3018-3023.

6. Lantner F, Starlets D, Gore Y, Flaishon L, Yamit-Hezi A, Dikstein R, Leng L, Bucala R, Machluf $Y$, Oren M, Shachar I: CD74 induces TAp63 expression leading to B-cell survival. Blood 2007, 110:4303-4311.

7. Leng L, Metz CN, Fang Y, Xu J, Donnelly S, Baugh J, Delohery T, Chen Y, Mitchell RA, Bucala R: MIF signal transduction initiated by binding to CD74. J Exp Med 2003, 197:1467-1476.

8. Stein R, Mattes MJ, Cardillo TM, Hansen HJ, Chang CH, Burton J, Govindan S, Goldenberg DM: CD74: a new candidate target for the immunotherapy of B-cell neoplasms. Clin Cancer Res 2007, 13:5556s-5563s.

9. Burton JD, Ely S, Reddy PK, Stein R, Gold DV, Cardillo TM, Goldenberg DM: CD74 is expressed by multiple myeloma and is a promising target for therapy. Clin Cancer Res 2004, 10:6606-6611.

10. Su Al, Wiltshire T, Batalov S, Lapp H, Ching KA, Block D, Zhang J, Soden R, Hayakawa M, Kreiman G, Cooke MP, Walker JR, Hogenesch JB: A gene atlas of the mouse and human protein-encoding transcriptomes. Proc Natl Acad Sci U S A 2004, 101:6062-6067.

11. Starlets D, Gore Y, Binsky I, Haran M, Harpaz N, Shvidel L, Becker-Herman S, Berrebi A, Shachar I: Cell-surface CD74 initiates a signaling cascade leading to cell proliferation and survival. Blood 2006, 107:4807-4816.

12. loachim HL, Pambuccian SE, Hekimgil M, Giancotti FR, Dorsett BH: Lymphoid monoclonal antibodies reactive with lung tumors. Diagnostic applications. Am J Surg Pathol 1996, 20:64-71.

13. Binsky I, Haran M, Starlets D, Gore Y, Lantner F, Harpaz N, Leng L, Goldenberg DM, Shvidel L, Berrebi A, Bucala R, Shachar I: IL-8 secreted in a macrophage migration-inhibitory factor- and CD74-dependent manner regulates $B$ cell chronic lymphocytic leukemia survival. Proc Natl Acad Sci US A 2007, 104:13408-13413.

14. Otten HG, van Ginkel WG, Hagenbeek A, Petersen EJ: Prevalence and clinical significance of resistance to perforin- and FAS-mediated cell death in leukemia. Leukemia 2004, 18:1401-1405.

15. Moriyama $\mathrm{H}$, Yonehara S: Rapid up-regulation of c-FLIP expression by BCR signaling through the PI3K/Akt pathway inhibits simultaneously induced Fas-mediated apoptosis in murine B lymphocytes. Immunol Lett 2007, 109:36-46.

16. de Totero D, Montera M, Rosso O, Clavio M, Balleari E, Foa R, Gobbi M: Resistance to CD95-mediated apoptosis of CD40-activated chronic lymphocytic leukemia B cells is not related to lack of DISC molecules expression. Hematol J 2004, 5:152-160.

17. de Totero D, Tazzari PL, Capaia M, Montera MP, Clavio M, Balleari E, Foa R, Gobbi M: CD40 triggering enhances fludarabine-induced apoptosis of chronic lymphocytic leukemia B-cells through autocrine release of tumor necrosis factor-alpha and interferon-gama and tumor necrosis factor receptor-I-II upregulation. Haematologica 2003, 88:148-158.

18. Kater AP, Dicker F, Mangiola M, Welsh K, Houghten R, Ostresh J, Nefzi A, Reed JC, Pinilla C, Kipps TJ: Inhibitors of XIAP sensitize CD40-activated 
chronic lymphocytic leukemia cells to CD95-mediated apoptosis. Blood 2005, 106:1742-1748.

19. Williams JF, Petrus MJ, Wright JA, Husebekk A, Fellowes V, Read EJ, Gress RE, Fowler DH: fas-mediated lysis of chronic lymphocytic leukaemia cells: role of type I versus type II cytokines and autologous fasL-expressing T cells. Br J Haematol 1999, 107:99-105.

20. Jones DT, Ganeshaguru K, Virchis AE, Folarin NI, Lowdell MW, Mehta AB, Prentice HG, Hoffbrand AV, Wickremasinghe RG: Caspase 8 activation independent of Fas (CD95/APO-1) signaling may mediate killing of B-chronic lymphocytic leukemia cells by cytotoxic drugs or gamma radiation. Blood 2001, 98:2800-2807.

21. Roue G, Lancry L, Duquesne F, Salaun V, Troussard X, Sola B: Upstream mediators of the Fas apoptotic transduction pathway are defective in B-chronic lymphocytic leukemia. Leuk Res 2001, 25:967-980.

22. Muller M, Scaffidi CA, Galle PR, Stremmel W, Krammer PH: The role of p53 and the CD95 (APO-1/Fas) death system in chemotherapy-induced apoptosis. Eur Cytokine Netw 1998, 9:685-686.

23. Poulaki V, Mitsiades CS, Mitsiades N: The role of Fas and FasL as mediators of anticancer chemotherapy. Drug Resist Updat 2001, 4:233-242.

24. Friesen C, Herr I, Krammer PH, Debatin KM: Involvement of the CD95 (APO-1/FAS) receptor/ligand system in drug-induced apoptosis in leukemia cells. Nat Med 1996, 2:574-577.

25. Friesen C, Fulda S, Debatin KM: Induction of CD95 ligand and apoptosis by doxorubicin is modulated by the redox state in chemosensitive- and drug-resistant tumor cells. Cell Death Differ 1999, 6:471-480.

26. Eichhorst ST, Muerkoster S, Weigand MA, Krammer PH: The chemotherapeutic drug 5-fluorouracil induces apoptosis in mouse thymocytes in vivo via activation of the CD95(APO-1/Fas) system. Cancer Res 2001, 61:243-248.

27. Wang S, Maeng H, Young DP, Prakash O, Fayad LE, Younes A, Samaniego F: K1 protein of human herpesvirus 8 suppresses lymphoma cell Fasmediated apoptosis. Blood 2007, 109:2174-2182.

28. Jenke AC, Eisenberger T, Baiker A, Stehle IM, Wirth S, Lipps HJ: The nonviral episomal replicating vector pEPI-1 allows long-term inhibition of bcr-abl expression by shRNA. Hum Gene Ther 2005, 16:533-539.

29. Berkova Z, Wang S, Wise JF, Maeng H, Ji Y, Samaniego F: Mechanism of Fas signaling regulation by human herpesvirus $8 \mathrm{~K} 1$ oncoprotein. J Natl Cancer Inst 2009, 101:399-411.

30. Tao RH, Berkova Z, Wise JF, Rezaeian AH, Daniluk U, Ao X, Hawke DH, Karp JE, Lin HK, Molldrem JJ, Samaniego F: PMLRARalpha binds to Fas and suppresses Fas-mediated apoptosis through recruiting C-FLIP in vivo. Blood 2011, 118:3107-3118.

31. Liu F, Song Y, Liu D: Hydrodynamics-based transfection in animals by systemic administration of plasmid DNA. Gene Ther 1999, 6:1258-1266.

32. Snow AL, Chen LJ, Nepomuceno RR, Krams SM, Esquivel CO, Martinez OM: Resistance to Fas-mediated apoptosis in EBV-infected B cell lymphomas is due to defects in the proximal Fas signaling pathway. J Immunol 2001, 167:5404-5411.

33. Gajate C, Mollinedo F: Edelfosine and perifosine induce selective apoptosis in multiple myeloma by recruitment of death receptors and downstream signaling molecules into lipid rafts. Blood 2007, 109:711-719.

34. Ogasawara J, Watanabe-Fukunaga R, Adachi M, Matsuzawa A, Kasugai T, Kitamura $Y$, Itoh N, Suda T, Nagata S: Lethal effect of the anti-Fas antibody in mice. Nature 1993, 364:806-809.

35. Friesen C, Fulda S, Debatin KM: Deficient activation of the CD95 (APO-1/ Fas) system in drug-resistant cells. Leukemia 1997, 11:1833-1841.

36. Stel AJ, Ten Cate B, Jacobs S, Kok JW, Spierings DC, Dondorff M, Helfrich W Kluin-Nelemans HC, de Leij LF, Withoff S, Kroesen BJ: Fas receptor clustering and involvement of the death receptor pathway in rituximabmediated apoptosis with concomitant sensitization of lymphoma B cells to fas-induced apoptosis. J Immunol 2007, 178:2287-2295.

37. Amoroso A, Hafsi S, Militello L, Russo AE, Soua Z, Mazzarino MC, Stivala F, Libra M: Understanding rituximab function and resistance: implications for tailored therapy. Front Biosci (Landmark Ed) 2011, 16:770-782.

38. Muller M, Wilder S, Bannasch D, Israeli D, Lehlbach K, Li-Weber M, Friedman SL, Galle PR, Stremmel W, Oren M, Krammer PH: p53 activates the CD95 (APO-1/Fas) gene in response to DNA damage by anticancer drugs. J Exp Med 1998, 188:2033-2045.

39. Friesen C, Fulda S, Debatin KM: Cytotoxic drugs and the CD95 pathway. Leukemia 1999, 13:1854-1858.
40. Timmer T, de Vries EG, de Jong S: Fas receptor-mediated apoptosis: a clinical application? J Pathol 2002, 196:125-134.

41. Takahashi H, Feuerhake F, Kutok JL, Monti S, Dal Cin P, Neuberg D, Aster JC, Shipp MA: FAS death domain deletions and cellular FADD-like interleukin 1 beta converting enzyme inhibitory protein (long) overexpression: alternative mechanisms for deregulating the extrinsic apoptotic pathway in diffuse large B-cell lymphoma subtypes. Clin Cancer Res 2006, 12:3265-3271.

42. Mielgo A, van Driel M, Bloem A, Landmann L, Gunthert U: A novel antiapoptotic mechanism based on interference of Fas signaling by CD44 variant isoforms. Cell Death Differ 2006, 13:465-477.

43. Wise JF, Berkova Z, Mathur R, Zhu H, Braun FK, Tao RH, Sabichi AL, Ao X, Maeng $H$, Samaniego F: Nucleolin inhibits Fas ligand binding and suppresses Fas-mediated apoptosis in vivo via a surface nucleolin-Fas complex. Blood 2013, 121:4729-4739.

44. Daniluk U, Kerros C, Tao RH, Wise JF, Ao X, Berkova Z, Samaniego F: The peptide derived from the lg-like domain of human herpesvirus $8 \mathrm{~K} 1$ protein induces death in hematological cancer cells. J Exp Clin Cancer Res 2012, 31:69.

45. Tamori Y, Tan X, Nakagawa K, Takai E, Akagi J, Kageshita T, Egami H, Ogawa $\mathrm{M}$ : Clinical significance of MHC class II-associated invariant chain expression in human gastric carcinoma. Oncol Rep 2005, 14:873-877.

46. Cuthbert RJ, Wilson JM, Scott N, Coletta PL, Hull MA: Differential CD74 (major histocompatibility complex Class II invariant chain) expression in mouse and human intestinal adenomas. Eur J Cancer 2009, 45:1654-1663.

47. Verjans E, Noetzel E, Bektas N, Schutz AK, Lue H, Lennartz B, Hartmann A, Dahl E, Bernhagen J: Dual role of macrophage migration inhibitory factor (MIF) in human breast cancer. BMC Cancer 2009, 9:230.

48. Meyer-Siegler KL, Iczkowski KA, Vera PL: Further evidence for increased macrophage migration inhibitory factor expression in prostate cancer. BMC Cancer 2005, 5:73

49. Meyer-Siegler KL, Iczkowski KA, Leng L, Bucala R, Vera PL: Inhibition of macrophage migration inhibitory factor or its receptor (CD74) attenuates growth and invasion of DU-145 prostate cancer cells. J Immunol 2006, 177:8730-8739.

50. Koide N, Yamada T, Shibata R, Mori T, Fukuma M, Yamazaki K, Aiura K, Shimazu M, Hirohashi S, Nimura Y, Sakamoto M: Establishment of perineural invasion models and analysis of gene expression revealed an invariant chain (CD74) as a possible molecule involved in perineural invasion in pancreatic cancer. Clin Cancer Res 2006, 12:2419-2426.

51. Nagata S, Jin YF, Yoshizato K, Tomoeda M, Song M, lizuka N, Kitamura M, Takahashi $\mathrm{H}$, Eguchi $\mathrm{H}$, Ohigashi $\mathrm{H}$, Ishikawa O, Tomita Y: CD74 is a novel prognostic factor for patients with pancreatic cancer receiving multimodal therapy. Ann Surg Oncol 2009, 16:2531-2538.

52. Kitange GJ, Carlson BL, Schroeder MA, Decker PA, Morlan BW, Wu W, Ballman KV, Giannini C, Sarkaria JN: Expression of CD74 in high grade gliomas: a potential role in temozolomide resistance. J Neurooncol 2010, 100:177-186.

53. Ong GL, Goldenberg DM, Hansen HJ, Mattes MJ: Cell surface expression and metabolism of major histocompatibility complex class II invariant chain (CD74) by diverse cell lines. Immunology 1999, 98:296-302.

54. Hansen HJ, Ong GL, Diril H, Valdez A, Roche PA, Griffiths GL, Goldenberg DM, Mattes MJ: Internalization and catabolism of radiolabelled antibodies to the MHC class-II invariant chain by B-cell lymphomas. Biochem J 1996, 320(Pt 1):293-300.

55. Ochakovskaya R, Osorio L, Goldenberg DM, Mattes MJ: Therapy of disseminated B-cell lymphoma xenografts in severe combined immunodeficient mice with an anti-CD74 antibody conjugated with (111)indium, (67)gallium, or (90)yttrium. Clin Cancer Res 2001, 7:1505-1510.

56. Griffiths GL, Mattes MJ, Stein R, Govindan SV, Horak ID, Hansen HJ, Goldenberg DM: Cure of SCID mice bearing human B-lymphoma xenografts by an anti-CD74 antibody-anthracycline drug conjugate. Clin Cancer Res 2003, 9:6567-6571.

57. Sapra P, Stein R, Pickett J, Qu Z, Govindan SV, Cardillo TM, Hansen HJ, Horak ID, Griffiths GL, Goldenberg DM: Anti-CD74 antibody-doxorubicin conjugate, IMMU-110, in a human multiple myeloma xenograft and in monkeys. Clin Cancer Res 2005, 11:5257-5264.

58. Stein R, Qu Z, Cardillo TM, Chen S, Rosario A, Horak ID, Hansen HJ, Goldenberg DM: Antiproliferative activity of a humanized anti-CD74 
monoclonal antibody, hLL1, on B-cell malignancies. Blood 2004, 104:3705-3711.

59. Stein R, Smith MR, Chen S, Zalath M, Goldenberg DM: Combining milatuzumab with bortezomib, doxorubicin, or dexamethasone improves responses in multiple myeloma cell lines. Clin Cancer Res 2009, 15:2808-2817.

60. Hertlein E, Triantafillou G, Sass EJ, Hessler JD, Zhang X, Jarjoura D, Lucas DM, Muthusamy N, Goldenberg DM, Lee RJ, Byrd JC: Milatuzumab immunoliposomes induce cell death in CLL by promoting accumulation of CD74 on the surface of B cells. Blood 2010, 116:2554-2558.

doi:10.1186/s13046-014-0080-y

Cite this article as: Berkova et al.: CD74 interferes with the expression of fas receptor on the surface of lymphoma cells. Journal of Experimental \& Clinical Cancer Research 2014 33:80.

Submit your next manuscript to BioMed Central and take full advantage of:

- Convenient online submission

- Thorough peer review

- No space constraints or color figure charges

- Immediate publication on acceptance

- Inclusion in PubMed, CAS, Scopus and Google Scholar

- Research which is freely available for redistribution 